\title{
The Application of a Mixed Teaching Model to the Academic English Teaching for Graduate Students at Inner Mongolia University
}

\author{
Zhiling Wu, Yongqing Guo, Li Wei* \\ Foreign Languages College, Inner Mongolia University, Hohhot, China \\ Email: *wzhi@imu.edu.cn
}

How to cite this paper: Wu, Z. L., Guo, Y. Q., \& Wei, L. (2020). The Application of a Mixed Teaching Model to the Academic English Teaching for Graduate Students at Inner Mongolia University. Creative Education, 11, 105-114.

https://doi.org/10.4236/ce.2020.112008

Received: January 8, 2020

Accepted: February 14, 2020

Published: February 17, 2020

Copyright $\odot 2020$ by author(s) and Scientific Research Publishing Inc. This work is licensed under the Creative Commons Attribution International License (CC BY 4.0).

http://creativecommons.org/licenses/by/4.0/

(c) (i) Open Access

\begin{abstract}
This paper explores the application of a mixed teaching model of Task-Based Learning (TBL), Collaborative-Inquiry Model (CIM) and MOOCs to the academic English teaching for graduate students at Inner Mongolia University, China. Teaching tasks of eight units are assigned for students to learn through the online course on MOOC in advance. Graduate students are grouped to work and cooperate with one another to complete the presentations of their learning results. A five-year teaching practice indicates that 1) graduate students appear more active in class than students taught in traditional class; 2 ) the writing quality of abstracts is greatly improved through the cooperative learning pattern; 3) students show more satisfaction for the course than ever before regarding the teacher's help for their academic activities. The application of the new teaching model has not only benefited the Inner Mongolia University (IMU) students, but also set up a pioneering example in teaching reform for graduate students and provided valuable experiences for other universities in ethnic areas.
\end{abstract}

\section{Keywords}

Mixed Teaching Model, Graduate Students, Academic English, Reading and Writing

\section{Introduction}

The English Syllabus for Non-English Major Postgraduates clearly points out that the teaching goal of graduate English is to enable students to master English as a tool for their own major learning, research and international exchanges. Postgraduates are to be cultivated to be those who are capable of writing and 
publishing English academic papers, participating in international academic conferences and exchanges and relatively smoothly reading the English literature and materials of the major (Ministry of Education of the People's Republic of China, 2007). This should be regarded as one of the most important criteria to evaluate the English teaching system and mode of postgraduates.

In order to understand the needs of non-English major graduate students of Inner Mongolia University for degree courses, the teacher made an investigation by employing questionnaires and interviews. Through the interview and questionnaire survey of non-English major graduate students enrolled in 2014 and 2015 at Inner Mongolia University, it reveals that there are four major needs for learning academic English for non-English major graduate students: $96.33 \%$ of graduate students want to achieve the goal of reading English literature by learning the course; $83.49 \%$ expect to write academic writings in English; 63.3\% hope to write emails and communicate with scholars in English; 52.29\% of them anticipate using English for oral communication as their respective principal objectives for learning the course.

According to the survey, $96.5 \%$ of graduate students did not receive any systematic training of academic English before entering the university; $98 \%$ of graduate students claimed that their only academic writing experience was writing their undergraduate papers for bachelor's degree; more than $85 \%$ of the students held the view that the biggest difficulty in English learning at the graduate stage was that they had no idea of the writing norms and discourse characteristics of English academic papers. The survey shows that graduate students are in urgent need of systematic guidance and training in reading and writing academic papers. Therefore, the cultivation of graduate students' academic English abilities should be at the core of graduate English teaching.

Since the fall of 2015, in order to meet the immediate needs of graduate students, based on the teaching guidelines from the university and graduate college, and through the scrupulous arrangement of the Foreign Languages College of Inner Mongolia University, the teaching team for graduate students has changed the traditional English teaching that once focused solely on developing students' basic language skills, into the general academic English teaching for cultivation of academic English abilities. This shift happened partly as a result of the inspection tour surveying English teaching situations for graduate students in more than fifty " 985 " and " 211 " universities in China. Those well-known universities aim to cultivate international communication abilities of graduate students in academic English. However, graduate students in ethnic areas have weak English foundation, low enthusiasm and lack of confidence in English learning, all of which lead to the complexity and peculiarities of English teaching for graduate students in ethnic areas. Currently, traditional teacher-centered teaching mode is mostly adopted in postgraduate English teaching in ethnic areas, which focuses solely on developing students' basic language skills, without cultivating academic English abilities of graduate students. In view of this, the members of the 
teaching team for graduate students at Inner Mongolia University have updated and improved the previous curriculum and teaching methods, carried out a mixed teaching model of TBL, CIM and MOOCs and made the classroom teaching reform adjusting to the learning needs and actual English level of graduate students in ethnic areas, with the aim of better reading ability leading to better writing ability, and the teaching team believes that good group member activities are able to promote each member's performance in writing. Thus the teaching team could scientifically guide the graduate English teaching at Inner Mongolia University to be more academic, practical, advanced and innovative. Accordingly, a five-year reform of academic English courses for graduate students has been carried out at Inner Mongolia University, exploring effective ways to improve students' academic English abilities in practice, and remarkable results have been achieved.

\section{The Characteristics of Academic English Teaching at Inner Mongolia University}

Graduate English course is a compulsory course for academic and professional masters at Inner Mongolia University. It lasts only 16 weeks in one semester, with a total of 64 class hours. Since 2015, Inner Mongolia University has begun to change the English teaching for graduate students from general English skills teaching to academic English teaching. Specifically, the focus of the teaching has gradually changed from the traditional teaching model focusing on basic language skills to the teaching system of the cultivation of academic English abilities. The English teaching for graduate students in ethnic areas mostly adopts the traditional teaching mode with English teachers dominating the class time with instructions and explanations while students' participation and enthusiasm are not high. The purpose of this paper is to explore the application of a mixed teaching model of TBL and CIM and MOOCs to the academic English teaching for graduate students in ethnic areas. It is intended that specific learning tasks motivate graduate students to cooperate in academic English learning (Ellis, 2003). The mixed academic English teaching model is shown in Figure 1.

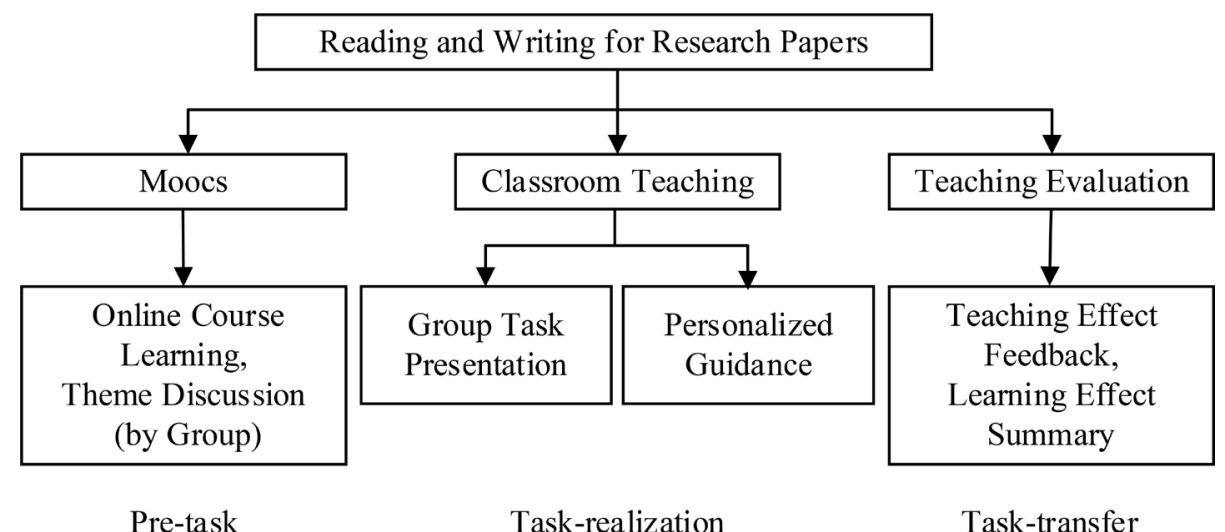

Figure 1. A mixed academic English teaching model of TBL, CIM and MOOCs. 


\subsection{General Academic English Teaching}

The reform and practice of English teaching for graduate students at our university involve students of every major and every college at the university. The characteristics and differences of arts and science disciplines have been taken into account. Therefore, the teaching team chooses the teaching materials and teaching methods commonly used in various disciplines, which are not based on the specific requirements of a particular discipline or major, but on the common applicability and all-purpose respect of academic English as a whole. The selected textbook of Inner Mongolia University is Reading and Writing for Research Papers published by Tsinghua University Press, which is divided into four topics and each topic has two units, including the understanding of plagiarism; the use of dictionaries; cross-cultural communication and EFL writing. The topic selection is closely related to students' English study and academic life, which can raise students' interest in reading research papers.

\subsection{Curriculum Design}

In our curriculum design, for the first two weeks, the teacher mainly focuses on teaching the overall ideas and methods of reading and writing research papers in class. According to the AIMRD (abstract, introduction, methods, results, discussion) paradigm commonly used in research papers of various disciplines, the teacher guides postgraduates to read and analyze the original research paper in this unit and gradually construct the basic elements of academic papers, and makes students understand and master academic norms, structure features and language features of academic discourses. The teacher motivates students to analyze the structure of one research paper, the author's point of view, the long and complex sentences, the language style and the characteristics of words and sentences in this academic article. In this way, students would get familiar with the argumentative language features of academic articles, build up their academic vocabulary, improve the efficiency of reading the academic articles, and grasp the topic sentences of the paragraphs and the logical relationship between them. Ultimately students could get important points of the article, distinguish the main ideas of different sections from their supporting details and read academic papers efficiently.

When encountering long and difficult sentences, graduate students are instructed to first analyze the sentence structure, and then understand the main point that the whole sentence conveys and subsequently, the logical relationship between them. Finally, they are asked to translate those sentences based on understanding, and refine them into authentic Chinese ones. In the practice of students' English-Chinese translation, students' translations could be rather illogical in the target language. Sometimes, although they correctly understand the original text, they unconsciously follow the sentence structure of the English source text, resulting in the translation being quite different from the Chinese expression habits. The most direct cause is that students do not have a systemat- 
ic and clear understanding of the overall and specific differences between English and Chinese. First of all, the teacher systematically imparts to the students the knowledge of the overall and specific differences between English and Chinese, so as to raise students' awareness of the differences between English and Chinese. The teacher then gives students some knowledge of the characteristics of both English and Chinese while they do the translation. And meanwhile they could apply the common methods and techniques in translation. Through practice, students would be familiar with translation skills, and improve their translation abilities. In the end, they increase their understanding of English and Chinese culture and thinking.

For the next fourteen weeks, the teacher first assigns teaching tasks of eight units for students to complete in a small group. The teaching of the unit includes the following important elements of a research paper: 1) abstract, 2) introduction, 3) methods, 4) results, 5) charts and data in the paper, 6) discussion, 7) references and annotations, 8) paraphrasing and summarizing. The teacher tells students that there is an online course "Academic Norms and Paper Writing", which could help them achieve their learning objectives if they learn it in advance through electronic devices including PC. The group members discuss and work with each other and complete the presentation of learning results through division of work and cooperation. The teacher mainly focuses on learning tasks and solving problems, and assists students in completing explorations of some problems. The teacher plays the role of guidance, supervision, management and evaluation. Secondly, the feedback evaluation of the group work is carried out in class, which is completed by teachers and students together. In the achievement exchange session, according to the report of each group, the teacher makes a quantitative evaluation of the group report and of each student's performance within the group. Students are asked to make assessments about each other's performance, and the teacher gives feedback.

\subsection{Questionnaire Survey of Teaching Situation}

Through the study of this course, $93.58 \%$ of the graduate students stated that they had got an overall understanding of academic English writing and the writing norms and discourse characteristics of academic papers in English, which was crucial for their reading English professional literature and writing academic papers. Through the study of this course, $89.91 \%$ said that they would consciously use the knowledge of the course to analyze the professional literature with what they had learned in class. $60.55 \%$ stated that while learning the course engaged them in undertaking tasks like giving presentations, they had found their problems and learned a lot from their classmates. 60.55\% had done enough preparations and developed their language abilities in the presentation session. In order to accomplish the task assigned by the teacher, they had learned to grasp the topic sentence of each paragraph, the logical relationship between paragraphs. 58.55\% stated after a period of study, they had mastered the reading 
skills of finding out the main points and supporting details of the academic writings. They could distinguish the argument from its supporting details, and figure out logical relations in the research paper. One student said. "It turns out that the article is so logical, which fosters my habit of deep reading and will be of great help to me in writing papers."

\subsection{General Academic English Writing Teaching}

According to the law of language learning, language input is the basis of language output, and high-quality language input lays the foundation for the writing of academic papers ( $\mathrm{Li}, \mathrm{Wu}, \& \mathrm{Shi}, 2017)$. The teaching of general academic English writing has combined reading and writing together, promoting writing abilities of graduate students through good reading, which, in turn, will eventually improve their writing abilities.

In terms of language output, the teacher uses task-based learning strategy to guide students to master the writing norms and writing skills of English academic paper step by step. Students are required to work with team members to write an abstract for a research paper in English. In the cooperative learning of the group, the more competent learners lead and inspire other partners to work on the task and make common progress consequently. The teaching method of Collaborative-Inquiry Model can help graduate students solve the difficulties encountered in their learning to write abstracts in English. Since students come from different disciplines, when arranging classes, the team tries to put them of the same department, the same major or similar majors in the same class. Thus graduate students in one class can form study groups to learn more effectively. Interaction among the same team proved to be conducive to improving academic English writing abilities of graduate students.

In order to test the effects of the shift from general English skills teaching to academic English teaching, abstract writing tests were conducted in the experimental class before and after teaching. In both tests, students were required to read an adapted English research paper and then write an abstract for it. A total of 60 students took part in two abstract writing tests. The test results show that the mixed teaching model of TBL and CIM and MOOCs can help students significantly improve their writing quality of abstracts through the cooperative learning pattern.

In the pre-test, most students' abstracts are wordy, which makes the abstract lengthy, not concise at all. In the content, these abstracts contain too much less important information, which makes the abstract seem very redundant, and not direct and to the point of the research, ruining the overall impression an abstract leaves on readers. As for the structure, students do not know how to use IMRD structure of the research paper to organize abstract sentences. The abstract is a summary of the research paper, but students tend to take too many original sentences in the paper to put them together, which is not only poorly conveyed in meaning, but also results in poor coherence. When it comes to grammar, there 
appear various grammatical problems such as lack of a subject, wrong use of infinitives, and inconsistency between the subject and the predicate, which all affect the quality of an abstract. In contrast, after the group work, the text quality of the abstract is significantly higher than that of the pre-test text, being clear, logic, concise, cohesive, and practically without mistakes in tense and voice. The change of text quality before and after reflected students' own perception and mastery of the writing norms for abstracts of academic papers. The final outcome is the crystallization of the efforts of the whole group and, and it has also witnessed the progress of each group member.

\subsection{Teaching Effects}

The reform of general academic English teaching for graduate students at Inner Mongolia University has benefited more than 1000 students (both academic and professional masters) over five years' time since its beginning, and has been widely applauded by graduate students of the university. As the main driving force of the mixed teaching is students, the implementation effect is generally reflected by the feedback of graduate students after class and their self-assessment of learning effects and curriculum satisfaction (Spanjers et al., 2015; Rahman et al., 2015; Ekwunife-Orakwue \& Teng, 2014; Owston et al., 2013).

Therefore, we conducted a questionnaire survey on the graduate students who learned the course. $93.58 \%$ of the students think that by studying the course of academic English reading and writing, they have got a clear idea about academic English writing. This course could make them apply knowledge to practice, helping them tremendously with their reading and writing of academic papers. Students' confidence in reading English literature independently is raised, and so does their confidence in writing and publishing English research papers.

According to the survey, $54.13 \%$ stated that they had realized the unique charm of the academic language and raised their interest and confidence in learning academic English well. 58.72\% claimed that their confidence in communication in academic English had been greatly strengthened so that some of them even had the idea of studying abroad to learn more from English experts. It also had greatly increased the proportion of students applying for the master's and doctoral overseas programs sponsored by China Scholarship Council and sponsored by Inner Mongolia University as well, and attending international conferences during their studies. Three supervisors of students for the master's degree were selected randomly from different colleges for open interviews. In the interviews, the supervisors also fully affirmed the improvement of students' English literature reading ability and academic paper writing ability during the semester. The statistical results given by the university indicated that papers published in international journals by these graduate students who had learned the course have been greatly improved in the past five years, not only in quality but also in quantity.

In these five years of the teaching reform, students' learning passion in Eng- 
lish is mobilized, and their learning abilities are developed in the process of using their own intellect. Students could use all kinds of mobile devices and PC terminals to obtain resources on the MOOC platform to study the related course in advance, and then make inquiries and carry out collaborative learning, which gives full play to the dominant role of students. We teachers as well as students profited from the Chinese University MOOC courses like "Academic Standardization and Paper Writing", which aims to cultivate students' academic English language skills, and the course "English for International Academic Exchange", which is intended to cultivate students' academic literacy and cross-cultural communication ability in academic English.

In line with the university's concept of combining research work with teaching practice, the teachers of this team attach more importance to research on academic English teaching in the last five years. The results of teachers' research work and teaching practice helped to elevate the overall classroom teaching level. Teachers of the team endeavor to keep up with the latest teaching techniques and bring about rewarding results of the teaching reform for graduate students at the university. Both the teacher and students have accomplished the task of learning, and the only difference is that students benefit from each other, from the teacher while the teacher grows with students and gains insight into how to make students learn better and how to improve their own abilities to meet the challenge from thoughtful students. Students' learning through the online course on MOOC beforehand is an input, which could be done by making use of fragmented time, and the teacher must ensure the input of the learning content in advance on the part of students. If they learn in advance, they would willingly participate in class activities and sharing of what they've learned. Interactivities between the teacher and the students, among the students themselves are increased, and a cooperative learning atmosphere is created, and the students appeared more active in class than students of the traditional class that solely learned English language skills for all those years. Students set up a task for themselves to learn with questions or problems before the class time, which results in better learning sense and abilities.

Students' satisfaction with the teaching reform and with the teacher is very high. The results from students' evaluation carried out by the university about the course and the teacher are more than 97 points out of 100 full points. The results of the questionnaire show almost the same evaluation results, which is rated as "excellent".

At present, our teaching concept, textbook updating, teaching content and teaching model can match with the first-class universities in China. The teaching reform at Inner Mongolia University and positive teaching effects are not only well received at the university, but also have exerted good influences on all universities of Inner Mongolia Autonomous Region. It strikes out a path of reform for English teaching at universities of the region. Its leading position is recognized among colleges and universities in ethnic areas. Now valuable experiences 
for other colleges and universities can be provided to make some changes in overdue teaching model in ethnic areas.

\section{Conclusion}

After five years' teaching practice, the academic teaching system and curriculum at Inner Mongolia University have been gradually improved, and some effective strategies and methods have been put forward to improve the academic English abilities of postgraduates at our university. At present, among all the colleges and universities in Inner Mongolia Autonomous Region, only Inner Mongolia University has changed graduate students' public English course into academic English course, which will provide valuable experiences and inspirations for carrying out the reform of public graduate English education in other colleges and universities in ethnic areas.

In the next five years, this course will further improve the timeliness of teaching with the help of modern teaching technology. With the help of the MOOC platform of Chinese universities, which provides rich and high-quality learning resources, an effective mixed academic English teaching model of TBL, CIM and MOOCs will be implemented better, which is more innovative, more advanced, and more challenging for both students and the teacher.

The teaching team is still exploring a better mixed academic English teaching model of TBL, CIM and MOOCs. Problems occurred too in the implementation of the teaching model. The teaching team is not scrupulous in detailing the teaching process; some learning session could only come true in a very ideal condition; and there are always a few students lagging behind with their assigned tasks, which will definitely affect the whole group, even the learning process of the whole class. These are some of the problems we have encountered that call for attention and ways out. Only when the teachers are harboring the right teaching philosophy, can this collaborative, task-based teaching model mixed with MOOC resources meet students' higher demands for the development of their academic thinking and abilities, which will eventually shape the academic future of graduate students.

\section{Conflicts of Interest}

The authors declare no conflicts of interest regarding the publication of this paper.

\section{References}

Ekwunife-Orakwue, K. C. V., \& Teng, T. L. (2014). The Impact of Transactional Distance Dialogic Interactions on Student Learning Outcomes in Online and Blended Environments. Computers \& Education, 78, 414-427. https://doi.org/10.1016/j.compedu.2014.06.011

Ellis, R. (2003). Task-Based Language Learning and Teaching. Oxford: Oxford University Press.

Li, Z., Wu, Z. X., \& Shi, B. H. (2017). Research on the Reform of Academic English 
Teaching Mode for Graduate Students in Agricultural and Forestry Colleges. Academic Degrees \& Graduate Education, 4, 56-59.

Ministry of Education of the People's Republic of China (2007). College English Curriculum Requirements. Beijing: Higher Education Press.

Owston, R., York, D., \& Murtha, S. (2013). Student Perceptions and Achievement in a University Blended Learning Strategic Initiative. The Internet and Higher Education, 18, 38-46. https://doi.org/10.1016/j.iheduc.2012.12.003

Rahman, N. A. A., Hussein, N., \& Aluwi, A. H. (2015). Satisfaction on Blended Learning in a Public Higher Education Institution: What Factors Matter? Procedia-Social and Behavioral Sciences, 211, 768-775. https://doi.org/10.1016/j.sbspro.2015.11.107

Spanjers, I. A. E., Könings, K. D., Leppink, J., Verstegen, D. M. L., Jong, N., Czabanowska, K., \& Merriënboer, J. J. G. (2015). The Promised Land of Blended Learning: Quizzes as a Moderator. Educational Research Review, 15, 59-74.

https://doi.org/10.1016/j.edurev.2015.05.001 